\title{
Controlled and extended release metoprolol reduced death, hospital admissions, and symptoms in chronic heart failure
}

\author{
Hjalmarson A, Goldstein S, Fagerberg B, et al, for the MERIT-HF Study Group. Effects of controlled-release metoprolol on \\ total mortality, hospitalizations, and well-being in patients with heart failure: the Metoprolol CR/XL Randomized \\ Intervention Trial in Congestive Heart Failure (MERIT-HF). JAMA 2000 Mar 8;283:1295-1302. \\ QUESTION: In patients with symptomatic chronic heart failure, do controlled and \\ extended release metoprolol succinate (a $\beta$-blocker) reduce mortality, hospital \\ admissions, and symptoms?
}

\section{Design}

Randomised (allocation concealed*), blinded (outcome assessor, \{patients, and clinicians $\} \uparrow$ ), , placebo controlled trial with a mean follow up of 1 year.

\section{Setting}

313 investigational sites in the US and 13 European countries.

\section{Patients}

3991 patients (mean age $64 \mathrm{y}, 78 \%$ men) who had had symptomatic heart failure (New York Heart Association [NYHA] class II to IV) for $\geq 3$ months, a decreased ejection fraction $(\leqslant 0.40)$, and a resting heart rate $\geq 68$ beats/minute and had received optimal treatment for $\geq 2$ weeks before randomisation. Exclusion criteria included acute myocardial infarction or unstable angina pectoris $\leqslant 28$ days before randomisation, indication or contraindication for $\beta_{1}$-blockers, severe decompensated heart failure, or supine systolic blood pressure $<100$ $\mathrm{mm} \mathrm{Hg}$. Patients with an ejection fraction between 0.36 and 0.40 were excluded if they exceeded 500 yards in a 6 minute walk test. All patients were included in the analysis.

\section{Intervention}

Patients were allocated to metoprolol $(\mathrm{n}=1990)$ or placebo $(\mathrm{n}=2001)$. The dose was started at $25 \mathrm{mg} /$ day $(12.5 \mathrm{mg} / \mathrm{d}$ for patients with NYHA class III or IV) and doubled every 2 weeks until the target dose of 200 $\mathrm{mg}$ /day was reached.

Source of funding:

For correspondence: Dr B Fagerberg,

Wallenberg Laboratory for Cardiovascular Research, Sahlgren-ska

University Hospital,

$S E-41345$

Gothenburg, Sweden.

Fax +4631885747

\section{Main outcome measures}

All cause mortality or any hospital admission, admission to hospital for worsening heart failure, and change in NYHA class.

\section{Main results}

Analysis was by intention to treat. The study was stopped early because interim analysis showed a 34\% reduction in mortality. Fewer patients in the metoprolol group AstraZeneca.

than in the placebo group died or were admitted to hospital $(p<0.001)$ or were admitted to hospital for worsening heart failure $(\mathrm{p}<0.001)$ (table). Patients in the metoprolol group were more likely to improve by 1 NYHA class $(26 \% v 24 \%)$ or 2 NYHA classes $(2.6 \% v$ $1.5 \%$ ) and were less likely to deteriorate in NYHA class than were patients in the placebo group $(p=0.003$ for trend).

\section{Conclusion}

In patients with symptomatic chronic heart failure, controlled and extended release metoprolol reduced mortality, hospital admissions, and symptoms.

*See glossary.

†Information provided by authors.

\section{COMMENTARY}

Our understanding of systolic heart failure in the past decade has evolved through a series of models, from cardiorenal (diuretics), to haemodynamic (inotropic and vasodilator treatment), to the more recent neurohormonal model. The earlier models all achieved the basic clinical need of symptomatic relief, but only the neurohormonal model has addressed morbidity and survival benefits. The earlier conceptual models labeled $\beta$-blockade as counterintuitive treatment, but $\beta$-blockers are now mandated in conjunction with angiotensin converting enzyme (ACE) inhibitors in patients who have chronic heart failure with systolic dysfunction.

Even in the face of overwhelming data supporting the use

Controlled and extended release metoprolol (Met) v placebo for symptomatic chromic heart failure $(H F) \ddagger$

\begin{tabular}{lllll} 
Outcomes at mean 1 year & Met & Placebo & RRR (95\% Cl) & NNT (Cl) \\
$\begin{array}{l}\text { All cause death or hospital } \\
\text { admission }\end{array}$ & $32 \%$ & $38 \%$ & $16 \%(9$ to 23$)$ & 17 (12 to 32) \\
\hline $\begin{array}{l}\text { Admission to hospital for } \\
\text { worsening HF }\end{array}$ & $10 \%$ & $15 \%$ & $32 \%(19$ to 42$)$ & 22 (15 to 39) \\
\hline
\end{tabular}

Abbreviations defined in glossary; RRR, NNT, and Cl calculated from data in article. 